Please send trade news information and illustrations to Arveen Bajaj at the $B D J$, Nature Publishing Group, The Macmillan Building, 4-6 Crinan Street, London N1 9XW. Trade news is provided as a service to readers using text and images from the manufacturer, supplier or distributor and does not imply endorsement by the BDJ. Normal and prudent research should be exercised before purchase or use of any product mentioned.

\section{Individual practice}

Sirona has launched a new design collection that enables dentists to style their practices to their own personal tastes and also create one that will make their patients feel relaxed and well looked after.

The collection offers three attractive themes: Savannah, Polar and Mediterranean. These styles allow the dentist to work in the warmth of the African sun, the cool of Polar nights or the tranquil beauty of Mediterranean landscapes.

The Sirona Collection incorporates many different combinations, which are available for all models in the Sirona treatment centre range. Each of these highly individual designs offers different combinations of upholstery colours, paintwork colours and themed graphics on the decor panels of the water unit.

To help dentists pick the perfect combination Sirona have created a colour configurator online at www.sirona.com/colourconfigurator The dentist can see at a glance what the treatment centre will look like "in-situ".

Reader response number 51

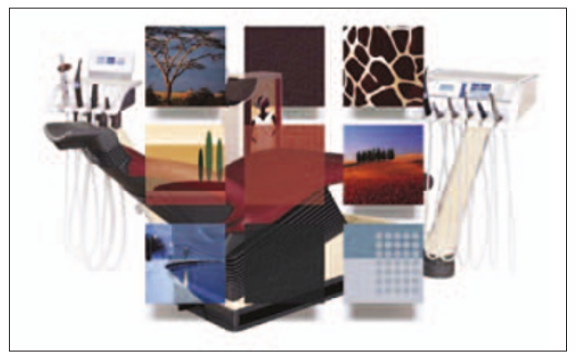

\section{Dental chair viewing}

The JazMedia Personal Theatre is an innovative product that allows patients to watch TV or DVDs with surround sound from the comfort of the dental chair. JazMedia Personal Theatre provides a solution for keeping your patients relaxed during long procedures, or distracting and entertaining younger patients during surgery.

The unit is lightweight, just $200 \mathrm{~g}$ and uses state-of-the-art macro-visual technology to project a virtual, 36-inch widescreen picture. Images can be delivered from a TV, DVD, VCR or camcorder, or alternatively you can connect it to a games console, guaranteed to keep even the most fidgety youngsters happy. Kent Express currently has two offers on the JazMedia player - the basic Personal Theatre package, for $£ 249$, or a complete wireless entertainment system for up to four surgeries within $100 \mathrm{~m}$ of the transmitter

\section{Free software}

From September DentalPlus will be giving everyone an introduction to its innovative practice management software by offering a free download of its Starter edition with Appointment book and Patient record keeping. Users will be able to load this onto any single computer, then create and manage appointments. The software is fully upgradeable to either the Associate or the full Professional editions.

The Associate edition adds to the Starter

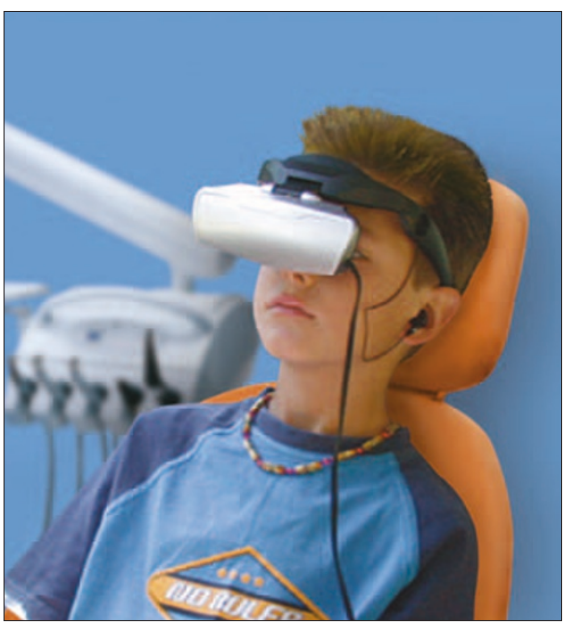

from $£ 499$. The wireless option includes a portable media player with the facility to record and playback TV shows, or movies stored on its hard drive, eliminating the need to keep DVDs in the surgery.

Reader response number 50

with a feature set enabling additional workstations, medical histories, charting, multiple treatment plans, patient financials, outgoing communications (documents, email, SMS), UDA monitor, directory of contacts, pre-set management reports and fully integrated Web-EDI.

The Professional edition has all that the Associate edition brings plus features including incoming and outgoing communications management, integrated VoIP, practice diary and reminder system.

Reader response number 52

\title{
Dental facility development solution
}

CareCapital specialises in the development of state-of-the-art, medium to large sized, dental facilities.

Design and functionality are inspired by innovative and successful Scandinavian care models, creating facilities that meet the challenges of delivering $21^{\text {st }}$ century dental care.

The company offers a turn-key solution which covers the entire development process, as well as providing a landlord- tenant relationship with a long term view.

Its partnerships with leading dental equipment suppliers allow it to tailor a dental facility uniquely around your requirements and patient base, whether it is a single site practice, nationwide dental chain, or an institution such as a dental school.

For more information visit www. carecapital.co.uk.

Reader response number 53

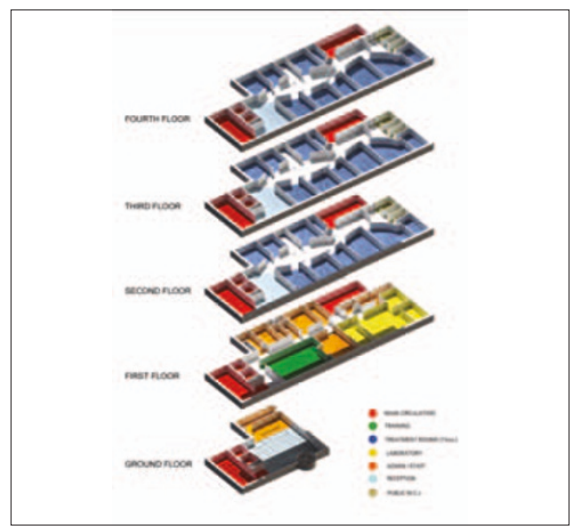




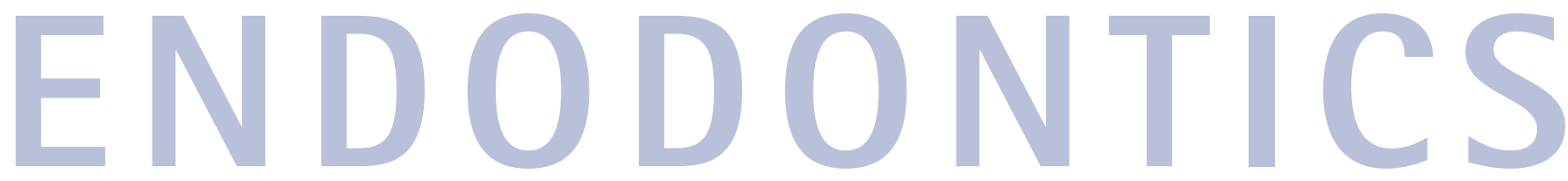

\section{All-in-one kit}

Dentsply Maillefer has launched the ProEndo Discovery Kit, an endo kit including materials and equipment required for cavity access, rotary root canal treatment, obturation and re-treatment.

The kit includes an X-Smart Endodontic motor with two autoclavable contra angles, three packs of NiTi ProTaper Universal treatment files, two packs of ProTaper Universal re-treatment files, re-treatment DMS IV solvent, new Senseus Flexofiles, Hedstroems and ProFinders, sealer, paper points and gutta percha points. A cavity access set is included and other accessories include glyde, mini-endo bloc and training blocs. Dentsply also provide training on all of the products, advising how they can be used to benefit your practice and clinical procedures.

\section{Reader response number 55}

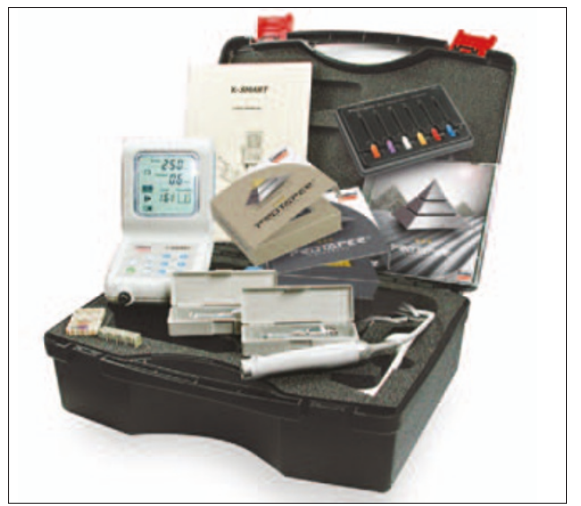

\section{Low viscosity}

Conseal f from SDI is a light cured fluoride releasing pit and fissure sealant. It has a low viscosity for optimal penetration enabling a direct, controlled flow. It is available in direct placement syringes, complets and bottles. The contra angled tips for both syringe and complet enable a controlled direct extrusion for faster procedures .

Reader response number 56

\section{The complete solution}

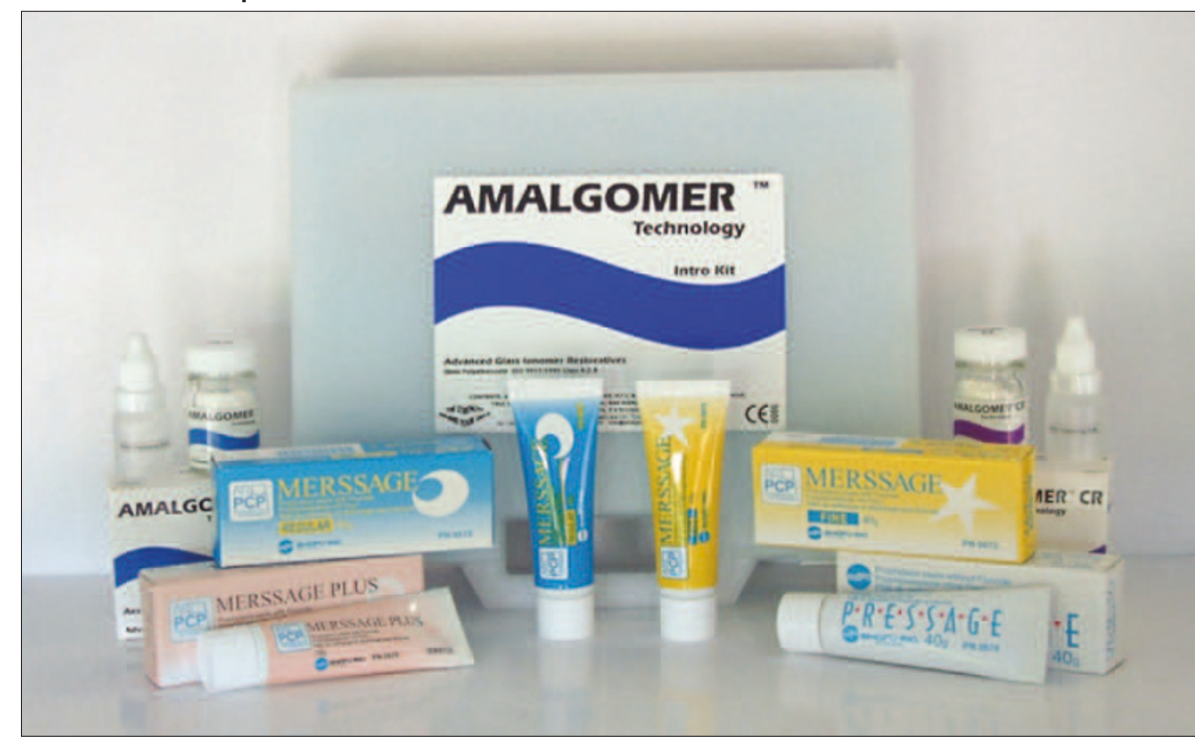

Amalgomer and Amalgomer CR, combine to provide a complete solution to restorative and conservative dentistry. In common with other glass ionomers they can be used in paediatric and geriatric dentistry, where they excel by virtue of their snap set to an exceptionally hard finish. It can be used in anterior fillings or as a freehand veneer

\section{Effective pain relief}

Ledermix Dental Paste is an anti-inflammatory and antibiotic treatment that is particularly useful in the emergency management of patients with irreversible pulpitis.

The product gives patients with irreversible pulpitis effective pain relief until definitive root canal treatment can be performed. It is simple to use, versatile and it can be used to fill canals after pulp extirpation during endodontic therapy. After application, the cavity can be closed with a cotton wool pledget and a temporary dressing. Ledermix Dental Paste has been designed to be water-soluble so it can be easily rinsed out of root canals. over its CR counterpart in posterior fillings.

It has ample wear resistance and all round strength to easily rival composites and amalgams with none of the fuss. Amalgomer CR is radiopaque and suitable for Class I \& II cavities and is ideal for core build-ups.

Reader response number 54

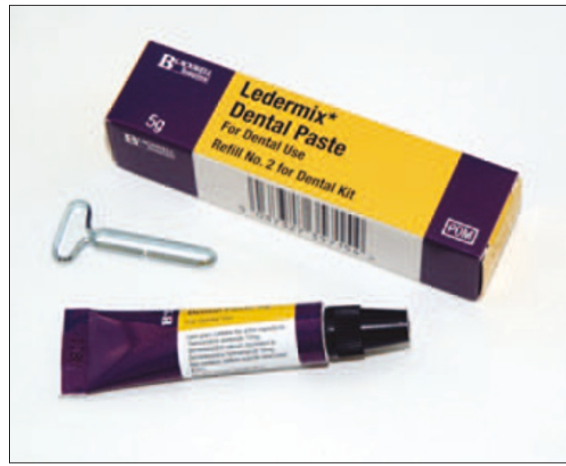

When canal preparation has been completed, obturation is then performed using your preferred material. It is available from from Blackwell Supplies.

Reader response number 57 


\section{Lower radiation CT}

\section{scanner}

At a radiation dose equivalent to only two DPT's per scan, the NewTom $3 \mathrm{G}$ is a safe way of accessing the anatomical information that only 3D radiography can provide.

The NewTom 3G requires 45\% less radiation per CT scan than any other comparable Cone Beam Volumetric Scanner and 10 to 20 times less radiation than a typical hospital CT scanner, the company claims. The radiation is automatically adjusted according to patient size/density, so there is no risk of incorrect exposure.

Full dentomaxillofacial imagery is available including: axial and tomographic views, maxilla/mandible panoramics, arch to arch occlusion, submental vertex,

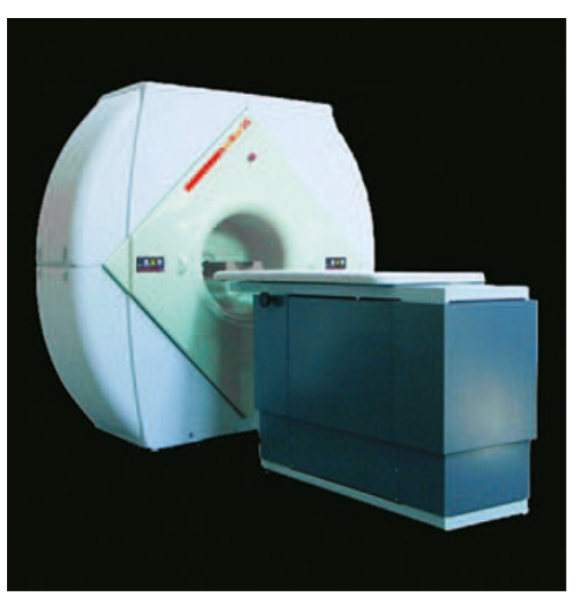

lateral and frontal views, and 3-D imaging and slicing of the skull, from any angle.

The NewTom 3G fits into a room $2.5 \mathrm{~m}$ $\mathrm{x} 2.5 \mathrm{~m}$ and servicing is a third of the cost of other CBVT machines.

Reader response number 58

\section{Versatile apex locator}

The Ray-pex 5 apex locator from Dentsply, projects the apical section and allows visualisation of the apical constriction,

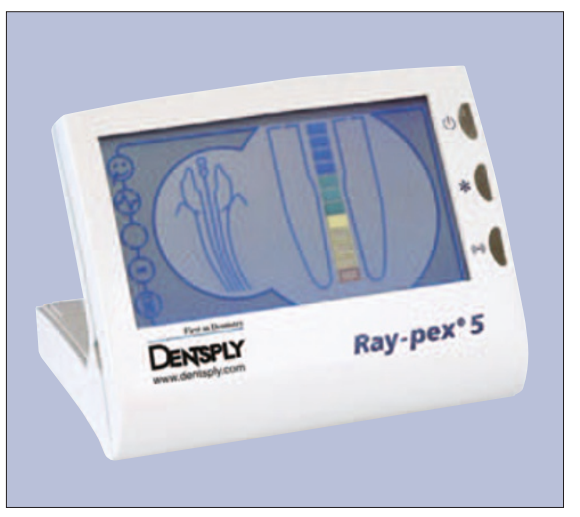

eliminating the need for calibration. Accurate working length is determined, based on electrical resistance.

The Ray-pex 5 has been calibrated on over 300 root canals and the gage indications have been calibrated correspondingly, avoiding over-instrumentation.

It works well with all metal instruments and is operational in most conditions while the unique foldable back-light display adjusts for easy viewing.

There is a built-in demo mode for quick demonstration and it prevents overextended or under-extended root fillings, without exposure to radiation.

Reader response number 59

\section{Fluoride releasing restorative}

Riva Silver from SDI is a mercury free fluoride releasing glass ionomer silver restorative which has strength, chemical adhesion, fluoride release and easy handling.

It releases high levels of fluoride, resulting in increased anticariogenic properties and improved longevity of the restoration. Its condensable nature allows the operator to quickly and easily place the restoration and can be packed using an amalgam condenser.

Its high compressive strength minimises the risk of fracture in the critical early stages after the restoration has been placed while the heat accelerated setting mechanism allows the material to "snap set".

The addition of metal particles into the cement substantially increases radiopacity

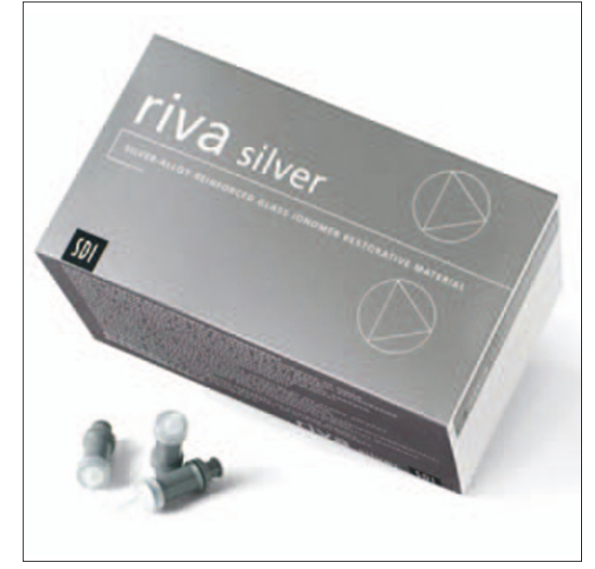

and it is easily differentiated from tooth structure, enabling easy diagnosis.

Reader response number $\mathbf{6 0}$ 